\title{
FOR SALE... BUT FOR HOW LONG? A METHODOLOGICAL PROPOSAL FOR ESTIMATING TIME-ON-THE-MARKET
}

\author{
Vanda C. S. MARTINS ${ }^{a}$, Marlene N. M. FILIPE ${ }^{\text {a }}$, Fernando A. F. FERREIRA ${ }^{b, c, *}$, \\ Marjan S. JALALI ${ }^{\text {b }}$, Nelson J. S. ANTÓNIO b \\ a School of Management and Technology, Polytechnic Institute of Santarém, Complexo Andaluz, Apar- \\ tado 295, 2001-904 Santarém, Portugal \\ b ISCTE Business School, BRU-IUL, University Institute of Lisbon, Avenida das Forças Armadas, \\ 1649-026 Lisbon, Portugal \\ ${ }^{c}$ Fogelman College of Business and Economics, University of Memphis, Memphis, TN 38152-3120, USA
}

Received 7 October 2013; accepted 8 July 2014

\begin{abstract}
Residential real estate assumes crucial importance in a country's socioeconomic development. It is an important field of study, and much work has gone into better understanding the sector and the factors determining sales within it, such as time-on-the-market (TOM). TOM can be influenced by a variety of elements; a fact that in effect raises a lot of issues, because these determinants are often interpreted in an ambiguous or unstructured way. This study aims to bring greater accuracy and structure to our understanding of these factors, by showing that the integrated use of cognitive mapping with the Analytic Hierarchy Process (AHP) can give rise to a conceptually coherent and empirically valid framework to calculate TOM indices in the residential real estate market. Because it takes into account both tangible and intangible characteristics of a house, this measurement framework also boosts strategic planning support and allows for more informed business planning, which we believe can be a real contribution to the development of the real estate market. The practical implications and limitations of this evaluation system are also discussed.
\end{abstract}

KEYWORDS: Residential real estate; Time-on-the-market; Decision support; Multiple criteria evaluation; Sustainable strategic planning

\section{INTRODUCTION}

Housing can be a key element in the economic and social development of a region or country. Changes in the housing market produce significant impacts on other sectors of economic activity and, consequently, on the well-being of populations (cf. Rybak, Shapoval 2011; Warren 2011). However, the real estate market is itself also affected by these very same markets and areas which it influences. As such, it is exposed to outbreaks of destabilization. In Portugal, for instance, the recent economic downturn and resulting instability have led to sweeping levels of pessimism, reflected in a negative trend and significant declines in the levels of intent and/or effectiveness in the construction and purchase of housing.

\footnotetext{
* Corresponding author. E-mail: fernando.alberto.ferreira@iscte.pt; fernando.ferreira@memphis.edu
}

Several studies, employing different methods and techniques, have been developed to try to understand the influence of a property's time-onthe-market (TOM) on the real estate sector. Still, such studies have generally been met with the challenges of accessing information in the housing market, the heterogeneity of the market itself, and the complexity and confidentiality of its transactions. Furthermore, there are methodological limitations common to most of these applications, such as the manner in which criteria are selected, or the methods used for calculating the weights between them (cf. Kardaras, Mentzas 1997; Ferreira et al. 2012; Ferreira 2013), which have limited existing research in the field.

This article aims to overcome some of these limitations, by defining and building TOM indices for the real estate market, following a multiple 
criteria approach to decision making, which ensures the principles of simplicity and transparency in the evaluation, definition and prediction of TOM. In particular, we will integrate cognitive mapping techniques with the Analytical Hierarchy Process (AHP) method developed by Saaty (1980), aiming to show that the integrated use of these two methods can give rise to a conceptually coherent and empirically valid framework to forecast TOM.

Cognitive maps are increasingly recognized as important tools for structuring complex problems, allowing the rate of omitted criteria to be reduced and promoting an underlying exchange of ideas (cf. Belton, Hodgkin 1999; Tegarden, Sheetz 2003; Eden, Ackermann 2004). At the same time, the AHP, understood as a technique for multiple criteria decision analysis (MCDA) based on mathematical algorithms and cognitive psychology (cf. Chauhan et al. 2008), helps decision makers overcome certain cognitive limitations, thus supporting them in making complex decisions (cf. Forman, Gass 2001). The prediction of TOM through this integrated approach can ultimately have a strategic planning purpose, assisting households, buyers, home sellers, investors and financial institutions that manage the underwriting risk related to housing finance and/or that deal with portfolio management.

The remained of this paper is structured as follows. The next section presents a general framework of the real estate sector, highlighting the limitations of the main evaluation models hitherto used. The following section presents the methodological framework of the system developed, and clarifies the relevance of the combined use of cognitive maps with the AHP technique to overcome some of the previously identified limitations. The ensuing section explains the design of the system developed. The final section concludes the article.

\section{MEASURING TOM: FUNDAMENTALS AND METHODOLOGIES}

The real estate sector can be broadly divided into two large categories: commercial and residential (cf. Hill 2011). It is a legally regulated activity, with two key areas of action: (1) the prospecting and gathering of information; and (2) the promotion of real estate. Known as a highly dynamic and heterogeneous market (cf. Catalão 2010), characterized by a lack of transparency in its transactions, it is an important element of any country's economy, as an indicator of its performance (cf.
Ebru, Eban 2009; Rybak, Shapoval 2011; Warren 2011; Ferreira et al. 2014a). In fact, since it is intrinsically associated with the functioning of the labor, financial, goods and services markets, any change in the housing market impacts those underlying markets as well. The downside, as Catalão (2010) points out, is that these relationships are mutual, which can lead to outbreaks of destabilization. Portugal at present provides a very good example of this, with the adverse economic context and the housing market mutually influencing each other to produce a negative evolutionary trend (cf. Catalão 2010; CGD 2011; PEH 2008/2013). This trend is reflected in high levels of pessimism regarding the financial situation and unemployment, which then feeds into lower levels of intention to buy and/or build housing. Thus, knowledge of the real estate market and the ability to formulate forecasts and intervention strategies within it emerge as issues of great utility, but are highly challenging due to the difficulty of accessing information on the housing market, a result of the complexity and confidentiality of its transactions (cf. Baryla, Zumpano 1995).

In practical terms, according to Cheng et al. (2008) and Springer and Worzala (2012), TOM is influenced by many factors that the seller does not completely control. Accordingly, a number of studies have been developed to understand the empirical relationship between the time variable and other characteristics or indicators of influence in the commercialization of a property, such as: house characteristics (e.g. Forgey et al. 1996); atypicality (e.g. Haurin 1988); location (e.g. Taylor 1999); state/quality (e.g. Chen, Rutherford 2012); and price (e.g. Anglin et al. 2003; Cheng et al. 2008; Hui, Yu 2012). It is not surprising, therefore, that different approaches and techniques for estimating market value and TOM (e.g. hedonic modeling and other mass appraisal techniques; non-parametric or semi-parametric regressions; spatial models that capture correlations within submarkets allowing for temporal asymmetry) have been suggested over the years (cf. Leung et al. 2002; Bourassa et al. 2003; Cheng et al. 2008; Peterson, Flanagan 2009; Carrillo, Pope 2012).

Despite the variety and dynamism revealed by these studies, it is worth noting that, like all research, they are not without their limitations. In particular, as Bin (2004) notes, they generally fail to provide insight into the relationships between the factors that influence residential real estate transactions and TOM, for instance: individual factors; seller's search cost and strategy; and mar- 
ket condition and maturity. Indeed, there is a considerable number of limitations that are common to most applications, and can be grouped into two major categories: (1) the way the evaluation criteria are selected and/or incorporated into the evaluation mechanisms; and (2) the way the weights between the evaluation criteria are calculated. In fact, it has been noted that not even the most promising models are exempt from such limitations, such that it would be of interest to promote the search for alternative methodologies (Wang et al. 2011). Following this, and because "caution [...] should be exercised [...]. Appropriate variables must be selected carefully and measured accurately" (Bourassa et al. 2010: 139), the development of a system that can support the construction of TOM indices in the residential property market, while overcoming these general methodological limitations, is a very relevant aim.

Indeed, the complexity of real estate decision processes, their inherent subjectivity and the multiple stakeholders with differing points of view involved, require a methodology that is both comprehensive and flexible enough to deal with such issues. An MCDA approach adopts a constructivist stance that is particularly suited to such decision problems, because it acknowledges and incorporates the underlying subjectivity, allowing a better structuring of the decision making process (Eden, Ackermann 2004; Saaty 2008). The combined use of cognitive mapping with AHP, in particular, as proposed and applied in the current study, presents important advantages in terms of the identification of determinant criteria and the calculation of the trade-offs between them, creating a framework which can complement and add to existing research. The next section describes our methodological approach in greater detail.

\section{BRIEF METHODOLOGICAL BACKGROUND}

This article adopts a constructive approach, based on methodologies that follow the fundamentals of the MCDA approach (for details, see Belton, Stewart 2002), namely the integrated use of cognitive mapping techniques with the AHP developed by Saaty (1980).

These techniques provide tools that facilitate the process of decision making and help "find the way in which the decision process must be handled" (Mateu 2002: 10). In fact, according to Belton and Stewart (2002: 2), "one of the principal aims of MCDA approaches is to help decision makers or- ganise and synthesize such information in a way which leads them to feel comfortable and confident about making a decision, minimizing the potential for post-decision regret, by being satisfied that all criteria or factors have properly been taken into account". In this logic, the AHP is presented as a possible option, within the universe of the multiple criteria approaches for this purpose. In fact, according to Forman and Gass (2001: 469), "the Analytic Hierarchy Process (AHP) is a methodology for structuring, measurement, and synthesis [of the three stages of decision making]" (see also Ong, Chew 1996; Bana e Costa et al. 1999; Belton, Stewart 2002; Ferreira et al. 2011).

Multiple criteria methodologies allow for the development of a structure accepted by all the participants, which in turn permits the homogenization of their knowledge about the problem under consideration and the creation of a "shared structure", agreed on by all as a result of discussion. In practice, through the association and organization of the decision-makers' preferences, a model of partial evaluation for each criterion can be constructed, and preferences then aggregated (cf. Bana e Costa et al. 1997). In fact, based on the exchange of value judgments among decision makers, these methods allow the development of key activities to obtain global results in the process of decision making. This results in: (1) a model of local preferences - partial evaluation of actions; (2) the determination of replacement rates (constant scale weights or trade-offs) among criteria; and (3) the determination of the impact of actions according to each criterion.

\subsection{Cognitive maps}

The Strategic Options Development and Analysis (SODA) stemmed from the need to support decision-makers (and facilitators) in structuring complex decision problems (cf. Ackermann, Eden 2010). In practice, by using cognitive mapping, it promotes dialogue among the stakeholders in a decision process and allows them to represent, structure and reorganize the fundamental ideas and concepts of the problem under analysis in real time. That is, "the SODA technology provides a ' $f a$ cilitative device' (in the form, for example, of formal 'maps' of peoples' thinking) which supports and better enables the negotiation of a collective vision" (Bryant 1997: 157). Belton and Stewart (2002: 48) reinforce this idea, stating that " $a$ cognitive map aims to represent the problem/issue as a decision maker (participant) perceives it, in the form of a means-ends network-like structure". 
In this line of reasoning, cognitive maps arise as tools to structure complex problems, whose main advantages are to allow a reduction in the rate of omitted criteria and promote learning, as a result of the exchange of ideas underlying the analysis of the relationships between criteria (cf. Belton, Hodgkin 1999; Tegarden, Sheetz 2003; Eden, Ackermann 2004). According to Ferreira et al. (2012), the SODA method is characterized by: (1) the ability to deal with qualitative factors; (2) the ability to structure difficult situations; (3) the provision of support for group work; and (4) being of great use in the development and implementation of strategic directions.

Because they are strongly related to the conviction of constructivism, cognitive maps are arguably very advantageous tools in structuring complex problems, while at the same time constituting an enriching experience for the decision makers involved, as it leads them to reconsider and/or reassess their points of view, altering and enhancing their perceptions of the problem (cf. Shaw 2004). In practice, the results translate into a strategic map, which because it results from the discussion among group members, belongs to all.

\subsection{Basics of the AHP technique}

The AHP is a multiple criteria decision analysis technique based on mathematical algorithms and cognitive psychology. It was developed in the 1970's by Saaty (cf. Saaty 1980), to help decision makers overcome their cognitive limitations and support them in making complex decisions (cf. Forman, Gass 2001). Characterized by its simplicity and ease of use (cf. Steuer, Na 2003; Pastor-Ferrando et al. 2010), strong mathematical support, and ability to analyze elements of both quantitative and qualitative, tangible or intangible nature, "the power and simplicity of the AHP has led to its widespread use throughout the world" (Forman, Gass 2001: 470) to systematize/solve a wide variety of decision problems in various contexts (cf. Ball, Srinivasan 1994; Schniederjans et al. 1995; Forman, Gass 2001; Shiau et al. 2002; Alonso, Lamata 2006; Pastor-Ferrando et al. 2010).

In practice, the AHP is based on an organized structure of pairwise comparisons of criteria or alternatives, thus allowing for analysis, quantification and/or assessments of elements which are not typically considered in traditional measurement scales; for example, those of a more qualitative or subjective nature. Indeed, the application of AHP depends on the stages of decision making, and is based on information provided by the stakeholders themselves (cf. Davies 1994; Saaty 1994; Bender et al. 2000; Forman, Gass 2001; Belton, Stewart 2002; Shiau et al. 2002; Perez-Gladish, M'Zali 2010; Nandi et al. 2011; Saaty, Chang 2011).

Briefly, the process is divided into "[...] three broad steps: the description of a complex decision problem as a hierarchy, the prioritization procedure and the calculation of results" (Chauhan et al. 2008: 610). In the structuring phase, the problem is aligned with the data provided by the stakeholders, and decomposed into a hierarchical structure that allows the relationships between goal/s, criteria, sub-criteria and alternatives involved in the decision process to be projected. In the evaluation phase, the data from the decision makers' earlier answers are consolidated, and pairwise comparisons of elements are carried out to create a set of preference arrays and/or impact levels, measuring both their relative and overall amounts (cf. $\mathrm{Xu}$, Zhang 2009). These comparisons are based on a scale for the measurement of judgment trials which varies between 1 and 9, where "1" reflects a criterion's lack of importance in relation to others and "9" reflects extreme importance (cf. Davies 1994; Alonso, Lamata 2006). Table 1 shows the meaning of the scale.

As pointed out by Dyer and Forman (1992), semantic judgments are a natural and simple way to project values, and pairwise comparisons are easy to make, discuss, justify and agree on. Saaty's fundamental scale then allows such semantic values and judgments to be converted into numbers. In this sense, the negotiation process established in an AHP-based framework, the respective pairwise comparisons and the filling in of value matrices are based on the semantic categories presented in Table 1. The next section will describe how the integrated use of cognitive maps with the AHP approach allowed the construction (and calculation) of TOM indices in the residential real estate market in Portugal.

\section{APPLICATION DEVELOPMENT}

As noted before, although empirical studies have previously been carried out to try to understand the relationship between a property's TOM and a series of influencing factors, we know of no previous studies attempting to do so through integrated use of cognitive mapping and AHP, which creates a flexible framework that can be continuously built upon to increase accuracy as new data emerges or is introduced into it. 
Table 1. The fundamental scale of absolute numbers

\begin{tabular}{|c|c|c|}
\hline $\begin{array}{l}\text { Intensity of } \\
\text { importance }\end{array}$ & Definition & Explanation \\
\hline 1 & Equal importance & Two activities contribute equally to the objective. \\
\hline 2 & Weak or slight & \\
\hline 3 & Somewhat more important & Experience and judgment slightly favor one activity over another. \\
\hline 4 & Moderate plus & \\
\hline 5 & Strong importance & Experience and judgment strongly favor one activity over another. \\
\hline 6 & Strong plus & \\
\hline 7 & $\begin{array}{l}\text { Very strong or demonstrated im- } \\
\text { portance }\end{array}$ & $\begin{array}{l}\text { An activity is favored very strongly over another; its dominance dem- } \\
\text { onstrated in practice. }\end{array}$ \\
\hline 8 & Very, very strong & \\
\hline 9 & Extreme importance & $\begin{array}{l}\text { The evidence favoring one activity over another is of the highest pos- } \\
\text { sible order of affirmation. }\end{array}$ \\
\hline $1.1-1.9$ & If the activities are very close & $\begin{array}{l}\text { May be difficult to assign the best value but when compared with } \\
\text { other contrasting activities the size of the small numbers would not be } \\
\text { too noticeable, yet they can still indicate the relative importance of the } \\
\text { activities. }\end{array}$ \\
\hline $\begin{array}{l}\text { Reciprocals } \\
\text { of above }\end{array}$ & $\begin{array}{l}\text { If activity } i \text { has one of the above } \\
\text { non-zero numbers assigned to it } \\
\text { when compared with activity } j \text {, } \\
\text { then } j \text { has the reciprocal value } \\
\text { when compared with } i\end{array}$ & A reasonable assumption. \\
\hline
\end{tabular}

Source: Saaty (2008: 257, adap.).

Following the methodological guidelines of Eden and Ackermann (2001: 22), who state that "the consultant [i.e. researcher] will relate personally to a small number (say, three to ten persons)", our study had the collaboration of five residential real estate experts (i.e. professional appraisers and realtors). These decision makers have been developing their professional activity over the past two to three decades in the Central-West region of Portugal. It should be highlighted, however, that the process-oriented approach followed in this study allows our framework to be seen as a learning mechanism and not as an end in itself or a tool to prescribe optimal solutions. This means that, with the necessary adjustments, the process can work well with a different group of decision makers. Two facilitators (i.e. researchers), responsible for conducting the negotiation process and recording the results, also participated in the group sessions - three intensive group meetings with an average duration of 4 hours.

The application of these techniques to the decision process was organized, as recommended by the literature, into the three main stages of decision support (cf. Bana e Costa et al. 1999; Belton, Stewart 2002; Ferreira et al. 2011): (1) the structuring phase, which was concerned with identifying indicators and key determinants of the speed of real estate sales by means of applying cognitive maps; (2) the evaluation phase, which focused on the application of the AHP approach to define the relative and global importance of each indicator or determinant; and (3) the recommendations phase, which explored the integrated use of cognitive maps and AHP, as a means of adding value to existing practices.

\subsection{The structuring phase}

In order to promote the decision makers' interest in TOM issues, the structuring phase began with the following trigger question: "Based on your own values and professional experience, what are the factors and/or characteristics of a house that most influence time-on-the-market?" Although the trigger question was quite broad, given the array of different residential properties available, the study (and model development) was guided toward the sale of apartments in particular, given the prevalence of this type of property in the context in question.

We then applied the "post-its technique", which involves writing on stickers (i.e. post-its), the criteria that, in the view of the decisionmakers, are relevant to the issue under study. In practice, the rules were simple: one criterion per post-it note, which must be marked with a minus 


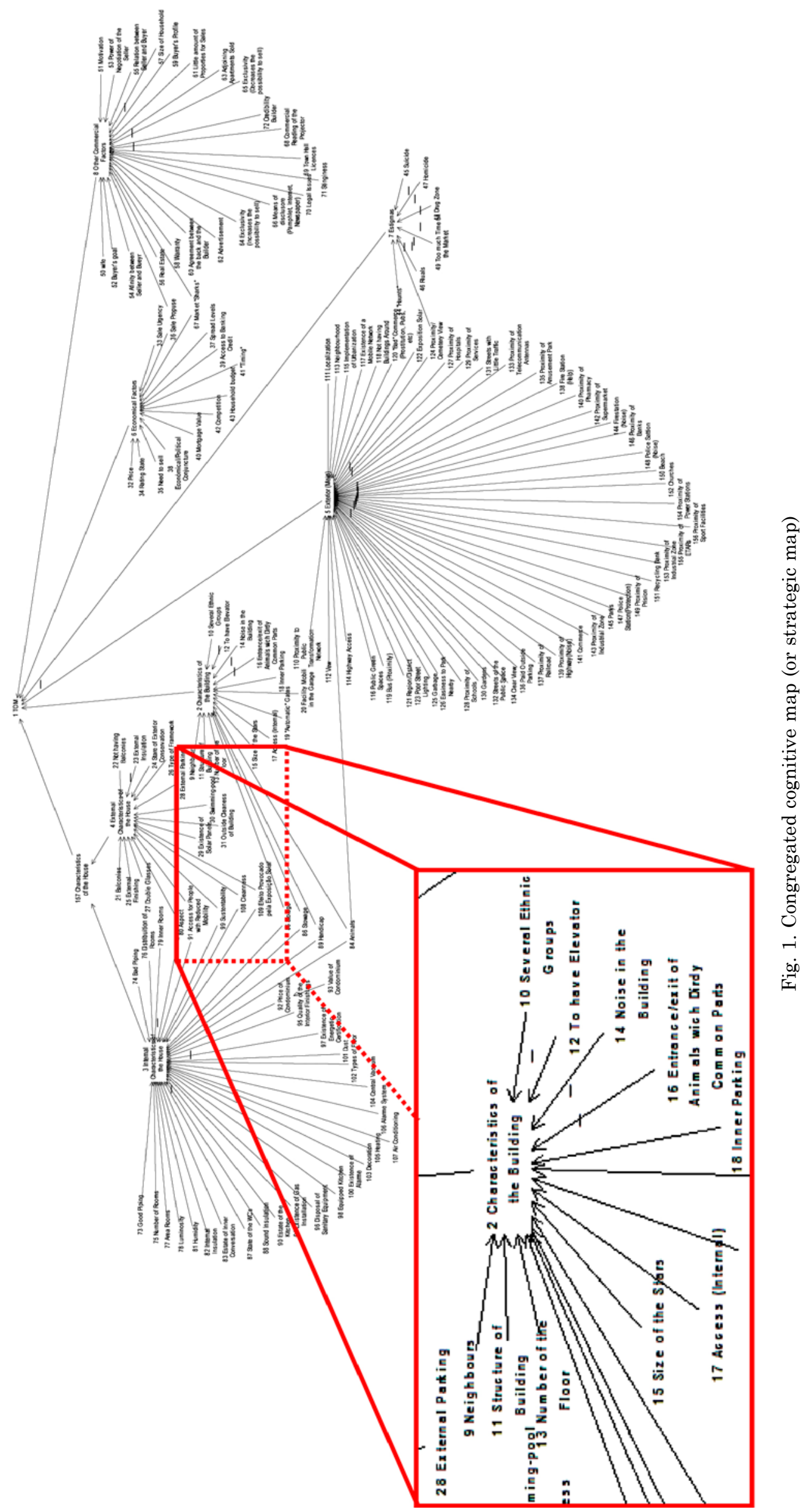


sign (-) in the upper right corner when the causeand-effect relationship is negative (cf. Ferreira et al. 2011). Once the number of criteria identified seemed to have reached its natural ceiling, the decision makers were asked to define and organize them by areas of concern or clusters, which resulted in the creation of seven clusters. Finally, the decision makers were asked to focus within each cluster, and to try, by means of discussion, to identify the relationships of causality between the criteria. In this way, hierarchies were defined between the criteria in each area of concern. Once the post-its technique had been applied, the $D e$ cision Explorer software (http://www.banxia.com) was used to develop a cognitive map of what had been discussed. This was then presented to the group to support further discussion regarding the structuring of the problem (Fig. 1).

Due to the process orientation of our study, Figure 1 represents the understanding of this particular group of decision makers, resulting from the negotiation process established among them. As such, the criteria and respective relationships were validated by the group after discussion and, therefore, the framework proposed should be seen as both the product of, and a tool for, a posture of learning. It is not a "final result", as such, nor a means for presenting optimal solutions. Although this can be seen as a limitation, it is more than compensated by the direct involvement of the experts, the amount of information discussed and by the iterative nature of the process, which allows ideas and thoughts to be shared and cause-andeffect relationships to be explored.

Given the decision-makers' arguments, and following the methodological guidelines of Keeney (1996), areas of interest were identified which supported the choice of criteria (CTRs). This resulted in the decision tree shown in Figure 2.

Following the groups' interpretation of the tree, $\mathrm{CTR}_{1}$ - Internal Characteristics of the House - concerns the internal physical characteristics of the house, namely piping condition, interior finishes and lighting. $\mathrm{CTR}_{2}-$ Exterior Characteristics of the House - addresses issues regarding the exterior physical characteristics of the house (e.g. exterior amenities, layout). $\mathrm{CTR}_{3}-$ Characteristics of the Building - highlights the physical characteristics of the building, such as state of conservation and plant. $\mathrm{CTR}_{4}-$ Exterior [Surroundings] - addresses issues related to the location of the house and its surrounding environment (e.g. neighborhood safety and reputation, proximity to economic agents, accessibilities). $\mathrm{CTR}_{5}-$ Stigmas - stands for so-

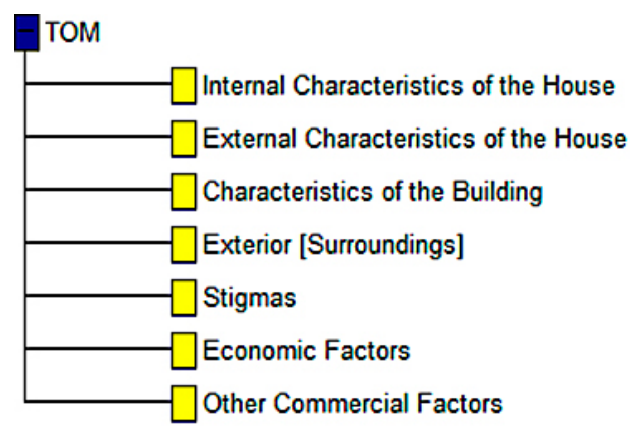

Fig. 2. Tree of criteria

cial stigmas (e.g. proximity to cemeteries, proximity to meth labs or known drug areas, haunting and ghosts and past deaths in the house). $\mathrm{CTR}_{6}-$ Economic Factors - underlines the importance of economic factors (e.g. taxes, financing conditions, housing supply). Finally, $\mathrm{CTR}_{7}-$ Other Commercial Factors - addresses commercial issues, such as advertising, motivation and credibility of the real estate agent.

In the second group work session, the decision makers focused their attention on the map and the tree of criteria, which had been developed based on the exercises and discussion of the first session. The aim was to carefully define, for each CTR, a descriptor and its respective impact levels (cf. Ferreira et al. 2014b). In practical terms, the decision makers identified, for each cluster, the five or six criteria that, in their perspective, were the most relevant. Then, using an adaptation of Fiedler's scale $(1965 ; 1967)$, they proceeded to define levels of partial performance, as well as to identify the reference levels used in each descriptor. Given that the descriptors could be qualitative, quantitative or mixed (cf. Ferreira et al. 2011), this approach proved easily manageable. For example, Figure 3 shows the descriptor of $\mathrm{CTR}_{1}$ - Internal Characteristics of the House (ICH).

As illustrated in the figure, $\mathrm{CTR}_{1}$ was operationalized by an index ICH, which brought together the five most important internal features of the house, from the decision makers' point of view. These were the condition of the pipes, the quality of the interior finishing, lighting, the state of internal conservation and the (lack of) humidity.

Impact level $\mathrm{L}_{1}$ represents the best possible performance, comprising an estate where the index (i.e. the sum of values assigned to each sub-criterion) belongs to the range of the maximum practicable values. In contrast, impact level $\mathrm{L}_{5}$ represents a clearly negative performance, indicating an estate classified by the minimum range of values. This procedure was repeated for the remaining six 


\begin{tabular}{|c|c|c|c|c|}
\hline \multicolumn{3}{|c|}{ Descriptor } & Level & Description \\
\hline Piping in very bad condition & 12345678 & Piping in excellent condition & $\mathbf{L 1}$ & $\mathrm{ICH} \in[35-40]$ \\
\hline Terrible interior finishes & 12345678 & Excellent interior finishes & Good & $\mathrm{ICH} \in[26-34]$ \\
\hline No lighting & 123345678 & Excellent lighting & Neutral & $\mathrm{ICH} \in[20-25]$ \\
\hline Bad state of internal conservations & 12345678 & Excellent state of internal conservations & $\mathbf{L 4}$ & ICH $\in[11-19]$ \\
\hline Lots of humidity & 123445678 & No humidity & L5 & ICH $\in[5-10]$ \\
\hline
\end{tabular}

Fig. 3. Descriptor and impact levels of the $\mathrm{CTR}_{1}$

CTRs. Once the descriptors for all the CTRs had been obtained, it was possible to proceed to the evaluation phase.

\subsection{The evaluation phase}

The evaluation phase took place in the last group session. In the first part of this session, based on the AHP methodology and the fundamental scale of Saaty (cf. Table 1), we proceeded to fill an array of value judgments for each of the defined descriptors. From these matrices, we obtained the scales of local preference. In practice, we asked the decision makers to jointly express their value judgments concerning pairwise comparisons between the levels defined for each descriptor.

The application of AHP in this context was supported by the use of the Super Decisions software (http://www.superdecisions.com/), which resulted, in the case of $\mathrm{CTR}_{1}$, in a partial score for $\mathrm{L}_{1}$ of $43.097 \%$ at the highest level, and a weight of $2.599 \%$ for the lowest level (i.e. $\mathrm{L}_{5}$ ). Levels considered by decision makers as Good and Neutral obtained weights of $32.849 \%$ and $16.950 \%$, respectively. It was also possible in this stage to determine slight variations with regard to differences between the first level and the Good level. The software furthermore allowed for minor adjust- ments to be made in cases where there were inconsistencies.

Figure 4 illustrates the procedure followed in completing the array of judgments for $\mathrm{CTR}_{1}$, as well as the numerical scale obtained. This scale was presented to the decision makers for validation and had an index mismatch of less than 0.10 (the consistency index allows the coherence of the matrix to be verified and its value is acceptable when it is lower than 0.10 (cf. Davies 1994; Saaty 1994; Xu, Zhang 2009; Perez-Gladish, M'Zali 2010)).

In order to obtain the trade-offs (also known as weights or replacement rates) between the seven CTRs, the decision makers were then asked to focus their attention on the CTRs and to proceed with their ordering based on their overall preferences. In practice, decision makers were asked to attribute the value " 1 " whenever a CTR was generally preferable to another, and " 0 " otherwise (Table 2). Additionally, it is worth noting that several mutual preferential independence tests were conducted to guarantee preferential independence among CTRs. This procedure is considered a prerequisite for the calculation of trade-offs (see Belton, Stewart 2012).

Once the ranking of the CTRs had been approved, we proceeded to the construction of a ma-

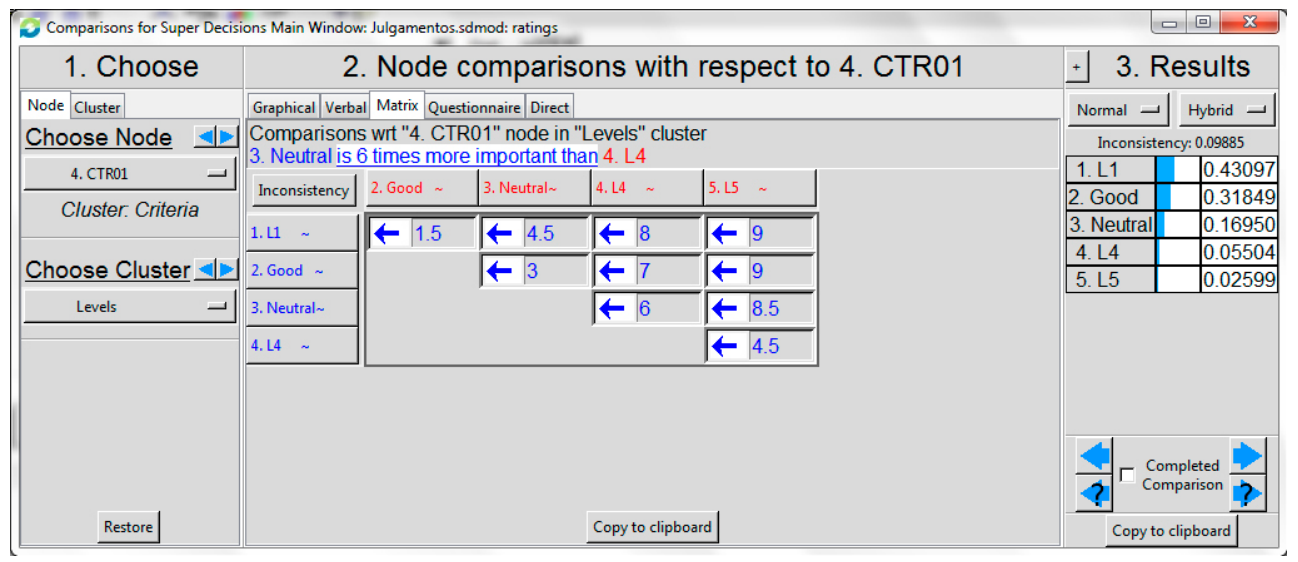

Fig. 4. Judgments and value scale of the $\mathrm{CTR}_{1}$ 
Table 2. Matrix of overall preferences

\begin{tabular}{|c|c|c|c|c|c|c|c|c|c|}
\hline & $\mathrm{CTR}_{1}$ & $\mathrm{CTR}_{2}$ & $\mathrm{CTR}_{3}$ & $\mathrm{CTR}_{4}$ & $\mathrm{CTR}_{5}$ & $\mathrm{CTR}_{6}$ & $\mathrm{CTR}_{7}$ & Total & Ranking \\
\hline $\mathrm{CTR}_{1}$ & -- & 1 & 1 & 0 & 0 & 0 & 1 & 3 & 4 \\
\hline $\mathrm{CTR}_{2}$ & 0 & -- & 1 & 0 & 0 & 0 & 1 & 2 & 5 \\
\hline $\mathrm{CTR}_{3}$ & 0 & 0 & -- & 0 & 0 & 0 & 1 & 1 & 6 \\
\hline $\mathrm{CTR}_{4}$ & 1 & 1 & 1 & -- & 0 & 0 & 1 & 4 & 3 \\
\hline $\mathrm{CTR}_{5}$ & 1 & 1 & 1 & 1 & -- & 0 & 1 & 5 & 2 \\
\hline $\mathrm{CTR}_{6}$ & 1 & 1 & 1 & 1 & 1 & -- & 1 & 6 & 1 \\
\hline $\mathrm{CTR}_{7}$ & 0 & 0 & 0 & 0 & 0 & 0 & -- & 0 & 7 \\
\hline
\end{tabular}

trix of peer-to-peer comparisons, in order to achieve the trade-offs. The decision makers were requested to express value judgments regarding the preferential difference between the CTRs, from which, by applying the AHP technique, the weights were obtained. Figure 5 illustrates this judgments matrix, as well as the numerical scale obtained, which was presented to the decision makers for discussion and validation. The index of inconsistency was 0.05772 (i.e. below 0.10).

After discussion, the trade-offs obtained were approved by the decision makers, and there was a consensual assignment of the greatest weight (i.e. $39.254 \%$ ) to $\mathrm{CTR}_{6}$; and of the lowest weight (i.e. $2.018 \%$ ) to $\mathrm{CTR}_{7}$. Having validated the tradeoffs, we proceeded to the application of the additive model presented in formulation (1), where $V(a)$ represents the overall score of alternative $a ; w_{i}$ is the weight of criterion $i$ and $v_{i}$ is the partial performance of the alternative analyzed in criterion $i$. $V(a)=\sum_{i=1}^{n} w_{i} v_{i}(a) ;$ with $\sum_{i=1}^{n} w_{i}=1$ and $0<w_{i}<1$

with $i=1, \ldots, n$.

We then proceeded to calculate overall scores for four "artificially designed" apartments (called Alphas). Table 3 shows the partial and global weights of each Alpha.

As Table 3 shows, the fictitious apartment Alpha 1 (hereafter "Great") obtains the highest scores on all the CTRs. Alpha 2 (hereafter referred to as "Good"), includes the "good" levels of all the CTRs. Alpha 3 is an apartment considered "Neutral", because it gathers the neutral levels of all the CTRs. Finally, Alpha 4 is an apartment with the worst performance on all the

Table 3. Impact levels and overall performance per Alpha

\begin{tabular}{lllllllll}
\hline & Overall & $\mathrm{CTR}_{1}$ & $\mathrm{CTR}_{2}$ & $\mathrm{CTR}_{3}$ & $\mathrm{CTR}_{4}$ & $\mathrm{CTR}_{5}$ & $\mathrm{CTR}_{6}$ & $\mathrm{CTR}_{7}$ \\
\hline Alpha 1 & 0.560359 & 0.43097 & 0.50119 & 0.51809 & 0.47975 & 0.62470 & 0.59269 & 0.41035 \\
Alpha 2 & 0.243897 & 0.31849 & 0.29135 & 0.24607 & 0.29535 & 0.21930 & 0.21454 & 0.33910 \\
Alpha 3 & 0.129288 & 0.16950 & 0.12923 & 0.15586 & 0.14237 & 0.12057 & 0.11867 & 0.13499 \\
Alpha 4 & 0.032259 & 0.02599 & 0.02866 & 0.02743 & 0.02998 & 0.03543 & 0.03240 & 0.04816 \\
Weights & & 0.09608 & 0.0525 & 0.03404 & 0.12917 & 0.27549 & 0.39254 & 0.02018 \\
\hline
\end{tabular}

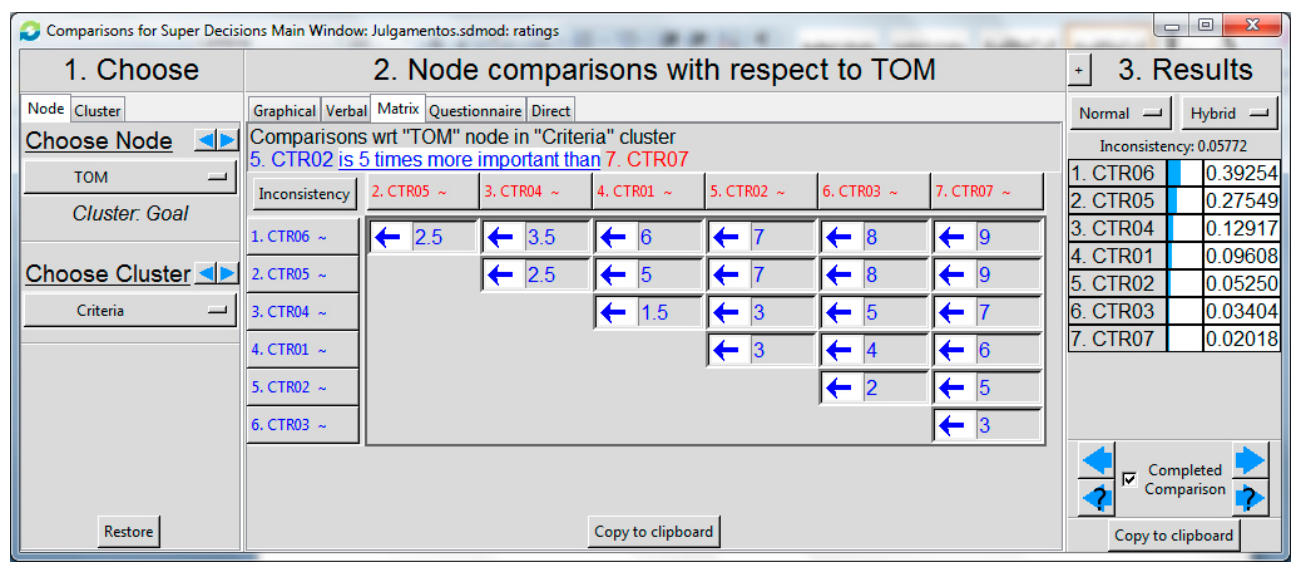

Fig. 5. Judgments matrix and trade-offs of the CTRs 
CTRs (hereafter "Terrible"). The decision makers were at this point invited to associate a selling time to each of the four Alphas, as a means of defining temporal anchors. It should be underlined that these estimated anchors were based on the perceptions projected by the decision makers after group negotiation and experience sharing. We are aware that this procedure is non-linear and inherently subjective, such that the estimated anchors are likely to be imprecise. However, it is worth noting that an important feature of the software used to support this process is that it allows for interactive explorations of changes in the inputs; such that the impact of a variation in any particular element on the model as a whole can immediately be seen. This offered an opportunity for further discussion, supporting the estimated anchors. Furthermore, the nature of the model is such that it is updated as new data is introduced, with the implication that after a certain amount of time, these anchors will be replaced with new ones based on actual/observed data. Table 4 shows the estimated time (in months) for the sale of each of the four fictitious apartments.

Table 4. Estimated anchors

\begin{tabular}{lll}
\hline Alpha & Overall score & $\begin{array}{l}\text { Estimated anchors } \\
{[\text { months] }}\end{array}$ \\
\hline Great & 0.560359 & 1 \\
Good & 0.243897 & 6 \\
Neutral & 0.129288 & 18 \\
Terrible & 0.032259 & 180 \\
\hline
\end{tabular}

In practice, considering the overall index and the anchor estimated (and later calculated) for each of the four Alfas, the use of linear interpolation makes it possible to estimate the TOM for any apartment. However, to validate the model and its practical application, sensitivity analyses were necessary to determine the consistency of results.

\subsection{Application of the (new) system and recommendations}

To analyze the results and, above all, to assess the practical relevance of the process followed and the system built, the next step consisted of testing the "new" of TOM, by analyzing a set of alternatives/ apartments. The decision makers were asked for actual information and data on apartments currently for sale or recently sold, with regard to the previously defined CTRs. Table 5 shows the result of the processing of information relating to a sample of six apartments in these conditions (identified as Delta 1 to Delta 6).

The partial performances of each Delta were identified, and then by applying the additive aggregation model (1), the total value of each one was calculated. Table 6 illustrates the overall scores of the apartments in the sample, as well as their respective ranking.

Table 6. Deltas' overall scores and respective ranking

\begin{tabular}{lll}
\hline & Overall score & Ranking \\
\hline Delta 1 & 0.33967 & 4 \\
Delta 2 & 0.37730 & 2 \\
Delta 3 & 0.31289 & 5 \\
Delta 4 & 0.23678 & 6 \\
Delta 5 & 0.41038 & 1 \\
Delta 6 & 0.36629 & 3 \\
\hline
\end{tabular}

Having calculated the overall scores, and based on the anchoring references shown in Table 4, the next step was to apply linear interpolation. Table 7 presents the evaluation exercise carried out with Delta 5. This Delta was chosen both because of its position and because it was an apartment which had already been sold, and therefore had a known TOM. This exercise also allowed for the calculation of the estimation error.

In practice, based on the references of anchoring and considering the overall score of Delta 5 (i.e. 0.410379), after applying the linear interpolation, we obtained an estimated TOM of 3.37 (i.e. three

Table 5. Deltas' partial performances

\begin{tabular}{llllllll}
\hline & CTR $_{1}$ & CTR $_{2}$ & CTR $_{3}$ & CTR $_{4}$ & CTR $_{5}$ & CTR $_{6}$ & CTR $_{7}$ \\
\hline Delta 1 & 0.43097 & 0.50119 & 0.24607 & 0.29535 & 0.6247 & 0.11867 & 0.33391 \\
Delta 2 & 0.43097 & 0.50119 & 0.24607 & 0.29535 & 0.6247 & 0.21454 & 0.33391 \\
Delta 3 & 0.16950 & 0.12923 & 0.24607 & 0.14237 & 0.6247 & 0.21454 & 0.33391 \\
Delta 4 & 0.05504 & 0.02866 & 0.05255 & 0.05255 & 0.6247 & 0.11867 & 0.13499 \\
Delta 5 & 0.43097 & 0.50119 & 0.51809 & 0.47975 & 0.6247 & 0.21454 & 0.33391 \\
Delta 6 & 0.43097 & 0.29153 & 0.24607 & 0.29535 & 0.6247 & 0.21454 & 0.33391 \\
\hline
\end{tabular}


Table 7. Estimated and effective/observed TOM for Delta 5

\begin{tabular}{llllll}
\hline Alfa/Delta & Overall score & $\begin{array}{l}\text { Estimated an- } \\
\text { chors [months] }\end{array}$ & $\begin{array}{l}\text { Estimated } \\
\text { TOM } \\
\text { a) }\end{array}$ & $\begin{array}{l}\text { Effective TOM } \\
\text { [sale] }\end{array}$ & Estimation error \\
\hline Great & 0.560359 & 1 & 1 month & -- & 3 months \\
Delta 5 & 0.410379 & -- & 3.37 & -- & 11 days \\
Good & 0.243897 & 6 & 6 months & -- & - \\
\hline
\end{tabular}

a) Linear interpolation.

Table 8. TOM predictions for Alphas and Deltas

\begin{tabular}{llllll}
\hline Alfa/Delta & Overall score & $\begin{array}{l}\text { Estimated an- } \\
\text { chors } \\
{[\text { months] }}\end{array}$ & $\begin{array}{l}\text { Effective an- } \\
\text { chors } \\
\text { a) }\end{array}$ & $\begin{array}{l}\text { Estimated } \\
\text { TOM } \\
\text { b) }\end{array}$ & TOM \\
\hline Great & $\mathbf{0 . 5 6 0 3 5 9}$ & 1 & -- & -- & 1 month \\
Delta 5 & 0.410379 & -- & 3 & -- & 3 months \\
Delta 2 & 0.377300 & -- & -- & 3.89 & 3 months +27 days \\
Delta 6 & 0.366293 & -- & -- & 4.06 & 4 months +2 days \\
Delta 1 & 0.339667 & -- & -- & 4.49 & 4 months +15 days \\
Delta 3 & 0.312891 & -- & -- & --90 & 6 months +27 days \\
Good & $\mathbf{0 . 2 4 3 8 9 7}$ & 6 & -- & 6.37 & 6 months +11 days \\
Delta 4 & 0.236778 & -- & -- & -- & 18 months \\
Neutral & $\mathbf{0 . 1 2 9 2 8 8}$ & 18 & -- & -- & 180 months \\
Terrible & $\mathbf{0 . 0 3 2 2 5 9}$ & 180 & -- & & \\
\hline
\end{tabular}

a) Effective TOM (actual value); b) Linear interpolation.

months +11 days). This proved to be extremely close to the apartment's actual TOM, which was of three months. Thus, the estimation error was of only 11 days. After ordering the Alphas and Deltas by their overall performance scores, we proceeded to estimate the TOM for the remaining set of Deltas (Table 8).

As Table 8 shows, the accuracy and precision of the model tend to increase with the introduction of new Deltas, because both the intervals between TOMs and the estimated errors are in this way reduced, when applying the linear interpolation. Moreover, estimated anchors gradually stop being used, and the model works only with effective an- chors (i.e. actual values). This phase was not only important for the consolidation of the results, but also resulted in a generalized feeling of satisfaction by the decision-makers, who recognized in the model an advance in the accuracy of estimating real estate sales and in the ability to formulate predictions to help guide business.

The final step consisted in carrying out sensitivity analyses in order to evaluate the implications of changes in the weights of each criterion. Figure 6 establishes the basis of this analysis with regard to $\mathrm{CTR}_{6}$ (considered the most important).

By way of example, Table 9 illustrates the sensitivity analysis conducted to $\mathrm{CTR}_{6}$.

Super Decisions Ratings
\begin{tabular}{|l|l|l|}
\hline & Totals & Priorities \\
\hline & 0.339667 & 0.166234 \\
\hline Delta1 & 0.377300 & 0.184651 \\
\hline Delta2 & 0.312891 & 0.153130 \\
\hline Delta3 & 0.236778 & 0.115880 \\
\hline Delta4 & 0.410379 & 0.200840 \\
\hline Delta5 & 0.366293 & 0.179265 \\
\hline Delta6 &
\end{tabular}

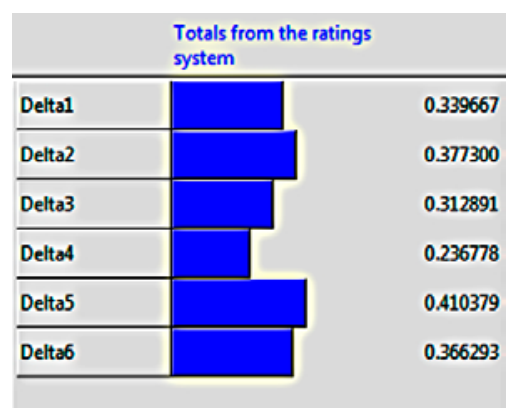

Fig. 6. Ranking of Deltas before sensitivity analysis (weight of $\mathrm{CTR}_{6}=0.39254$ ) 
Table 9. Sensitivity analysis on $\mathrm{CTR}_{6}$

\begin{tabular}{|c|c|c|c|c|c|c|}
\hline \multirow[t]{2}{*}{ Weight $\mathrm{CTR}_{6}$} & \multicolumn{6}{|l|}{ Priorities } \\
\hline & Delta 1 & Delta 2 & Delta 3 & Delta 4 & Delta 5 & Delta 6 \\
\hline \multirow[t]{2}{*}{0.050090} & 0.178698 & 0.180137 & 0.141258 & 0.126308 & 0.200105 & 0.173493 \\
\hline & 3 & 2 & 5 & 6 & 1 & 4 \\
\hline \multirow[t]{2}{*}{0.150070} & 0.176174 & 0.180700 & 0.143216 & 0.125663 & 0.199952 & 0.174295 \\
\hline & 3 & 2 & 5 & 6 & 1 & 4 \\
\hline \multirow[t]{2}{*}{0.200060} & 0.174815 & 0.181004 & 0.144270 & 0.125316 & 0.199870 & 0.174726 \\
\hline & 3 & 2 & 5 & 6 & 1 & 4 \\
\hline \multirow[t]{2}{*}{0.250050} & 0.173384 & 0.181323 & 0.145379 & 0.124950 & 0.199783 & 0.175181 \\
\hline & 4 & 2 & 5 & 6 & 1 & 3 \\
\hline \multirow[t]{2}{*}{0.340004} & 0.171877 & 0.181659 & 0.146548 & 0.124565 & 0.199691 & 0.175659 \\
\hline & 4 & 2 & 5 & 6 & 1 & 3 \\
\hline \multirow[t]{2}{*}{0.350030} & 0.170286 & 0.182014 & 0.147783 & 0.124159 & 0.199595 & 0.176165 \\
\hline & 4 & 2 & 5 & 6 & 1 & 3 \\
\hline \multirow[t]{2}{*}{0.392540} & 0.164934 & 0.183208 & 0.151933 & 0.122791 & 0.199270 & 0.177864 \\
\hline & 4 & 2 & 5 & 6 & 1 & 3 \\
\hline \multirow[t]{2}{*}{0.450010} & 0.166823 & 0.182787 & 0.150468 & 0.123274 & 0.199385 & 0.177264 \\
\hline & 4 & 2 & 5 & 6 & 1 & 3 \\
\hline \multirow[t]{2}{*}{0.500000} & 0.164934 & 0.183208 & 0.151933 & 0.122791 & 0.199270 & 0.177864 \\
\hline & 4 & 2 & 5 & 6 & 1 & 3 \\
\hline \multirow[t]{2}{*}{0.549990} & 0.161776 & 0.183913 & 0.154382 & 0.121984 & 0.199079 & 0.178866 \\
\hline & 4 & 2 & 5 & 6 & 1 & 3 \\
\hline \multirow[t]{2}{*}{0.599980} & 0.158291 & 0.184690 & 0.157085 & 0.121093 & 0.198868 & 0.179973 \\
\hline & 4 & 2 & 5 & 6 & 1 & 3 \\
\hline \multirow[t]{2}{*}{0.649970} & 0.154427 & 0.185552 & 0.160082 & 0.120106 & 0.198633 & 0.181200 \\
\hline & 5 & 2 & 4 & 6 & 1 & 3 \\
\hline \multirow[t]{2}{*}{0.699960} & 0.150118 & 0.186513 & 0.163424 & 0.119005 & 0.198372 & 0.182568 \\
\hline & 5 & 2 & 4 & 6 & 1 & 3 \\
\hline
\end{tabular}

It is worth noting that the values presented in the first column of Table 9 were generated by the Super Decisions software, and stand for possible oscillations in the weight of $\mathrm{CTR}_{6}$. The remaining columns present the Deltas' overall scores that resulted from those fluctuations. The sensitivity analysis carried out for $\mathrm{CTR}_{6}$ shows the robustness of the model, because the weight of this criterion can vary over a significant range of oscillation without violating the position of the Deltas (indicated in each cell's sub-line). The same analysis was performed with similar results for all the CTRs.

It is worth noting that despite the decision makers' receptivity and satisfaction with the results obtained, and the versatility of the technical procedures used, it is important to bear in mind that this study adopted a constructivist and learning perspective, where the results came from discussions between the elements of a specific group of decision makers. In this sense, this work should be viewed as a tool for negotiation and learning, rather than one intended to dictate definitive solutions. Furthermore, given the idiosyncratic characteristics of the methods (i.e. the results depend on the context and actors involved), any generalizations or extrapolations should be made with caution, and sensitivity analyses are recommended whenever there are adaptations to the model. On the other hand, the combined use of cognitive maps with the AHP approach allowed for additional adjustments which increased the potential of the original proposition.

\section{CONCLUSIONS}

Cheng et al. (2010: 109) argue that "choosing the optimal holding period is an important part of real estate investment decisions, because "when to sell" affects "whether to buy"'. Indeed, TOM predictions are important for a variety of stakeholders, ranging from households, buyers and home sellers, to 
investors and financial institutions. Taking the importance of the housing sector in socio-economic development as its starting point, this study aimed to contribute to a better understanding of the real estate market, by furthering our understanding of properties' TOM and the factors which can influence it.

In their examination of behavioral influences on judgments of the relative weights of criteria, Weber and Borcherding (1993) argue that there is no one superior method, but rather the choice of method should depend on the decision context. Given the decision context under consideration in this study, its complexity and subjectivity in particular, the methods applied seem particularly suited, because group dynamics allow people to learn and to alter and enhance their perceptions, clarifying and improving understanding of decision situations.

Most extant research in this area has suffered from certain common methodological limitations, regarding the choice and weighting of determining criteria of TOM (cf. Kardaras, Mentzas 1997). Thus, the option was for a methodology which, while having limitations of its own, had not previously applied to the field, and was able to overcome many of these previously encountered shortcomings. The use of cognitive maps allowed different individuals' opinions to be aggregated in a shared framework within which cause-and-effect relationships between variables could be detected and understood. And the use of AHP allowed the resulting criteria to be evaluated and weighted according to their perceived influence in the decision process.

While in our study this was specifically developed with a group of professional appraisers and realtors, the framework can be used and adapted to enhance understanding of how different market segments, buyers with differing preferences or sellers with distinct priorities operate. In this sense, our proposal is not a substitute for statistical approaches; however, its application by managers and decision makers can provide insights on the role of key feedback loops in the system, which might otherwise go undetected by statistical approaches alone.

With the active collaboration of five residential real estate experts (professional appraisers and realtors), who have been working in this field for two to three decades, we were able to integrate cognitive maps with MCDA methodologies, AHP in particular. This allowed us to construct a model that was not only robust, as shown by the sensi- tivity analyses, but also simple and transparent. Indeed, the use of cognitive mapping allowed ideas and thoughts to be shared and cause-and-effect relationships between criteria to be explored, allowing questions such as "why does this happen?" to be answered. When integrated with an MCDA framework like the AHP, which relies on pairwise comparisons, these characteristics can offer valuable contributions to existing frameworks, allowing the number of omitted variables to be decreased and the calculation of trade-offs to be facilitated, while adding simplicity and transparency to the decision process.

At the practical level, such models can be of great use to all those operating in the real estate market, be they agencies, brokers or real estate builders, or even individual buyers or sellers. Although as noted before, due precautions are required in generalizing the results of such exercises, it is important to note that much of their value resides in the processes themselves, and in the learning process associated with the application of techniques that, adopting a constructivist logic, reward the opportunity to reflect on the assessments and make suggestions for improvement. From a theoretical perspective, the application of MCDA systems, and the integration of cognitive maps with AHP in the real estate market in particular, are to the best of our knowledge a novel application of these methodologies, and as such provide an advance in their use and understanding.

In terms of future research, to compare the strengths and weaknesses of our framework to other methods, and to explore its integration within established frameworks (e.g. hedonic modeling and other mass appraisal techniques) is part of our longer term aim. Indeed, given that the application of MCDA techniques can help overcome some of the limitations identified in previous research, but also itself presents certain weaknesses, a comprehensive comparison of studies taking different epistemological stands and using distinct methodologies with regard to TOM, would appear to be of great use to all the stakeholders involved in the residential real estate sector. Indeed, such a project could help identify not only the relative pros and cons of different approaches, but also the points of complementarity between them, with a view to achieving a more comprehensive understanding of the issue. It would also be of interest to replicate the process in other countries; in addition to embedding a model risk in our framework, conducting similar studies using other MCDA methods, or carrying out comparative analyses. Finally, it would 
be of particular relevance, in terms of increasing the generalizability of the process and its strength, to replicate the process with different actors. Indeed, the framework is flexible enough to allow for such adaptations, and this could mean developing models akin to the one presented here, using not only real estate experts, but groups comprising both sellers and buyers for instance. This would not only greatly enrich the discussions and negotiation process, allowing a broadening of perspectives, but could also contribute to our understanding of the processes whereby buyers and sellers reach an agreement.

\section{ACKNOWLEDGMENTS}

The authors gratefully acknowledge the superb contribution and infinite willingness of the panel members (i.e. appraisers and realtors): Bruno Guerreiro, Carlos Gonzaga, Henrique Querido, João Lourenço and Paula Gonçalves. Institutional and facility support from the ISCTE Business School, University Institute of Lisbon, Portugal, is also acknowledged.

\section{REFERENCES}

Ackermann, F.; Eden, C. 2010. Strategic options development and analysis, in Reynolds, M.; Holwell, S. (Eds.), Systems approaches to managing change: a practical guide, London: Springer, 135-136. http:// dx.doi.org/10.1007/978-1-84882-809-4_4

Alonso, J.; Lamata, M. 2006. Consistency in the analytic hierarchy process: a new approach, International Journal of Uncertainty, Fuzziness and Knowledge-Based Systems 14(4): 445-459. http://dx.doi. org/10.1142/S0218488506004114

Anglin, P.; Rutherford, R.; Springer, T. 2003. The tradeoff between selling price of residential properties and time-on-the-market: the impact of price setting, Journal of Real Estate Finance and Economics 26(1): 95-111. http://dx.doi.org/10.1023/A:1021526332732

Ball, J.; Srinivasan, V. 1994. Using the analytic hierarchy process in house selection, Journal of Real Estate Finance and Economics 9(1): 69-85. http://dx.doi. org/10.1007/BF01153589

Bana e Costa, C.; Ensslin, L.; Corrêa, E.; Vansnick, J. 1999. Decision support systems in action: Integrated application in a multicriteria decision aid process, European Journal of Operational Research 113(2): 315-335. http://dx.doi.org/10.1016/S03772217(98)00219-7

Bana e Costa, C.; Stewart, T.; Vansnick, J. 1997. Multicriteria decision analysis: some thoughts based on the tutorial and discussion sessions of the ESIGMA meetings, European Journal of Operational Research 99(1): 28-37. http://dx.doi.org/10.1016/S03772217(96)00380-3
Baryla, E.; Zumpano, L. 1995. Buyer search duration in the residential real estate market: the role of the real estate agent, Journal of Real Estate Research 10(1): 1-13.

Belton, V.; Hodgkin, J. 1999. Facilitators, decision makers, D.I.Y. users: is intelligent multicriteria decision support for all feasible or desirable?, European Journal of Operational Research 113(2): 247-260. http:// dx.doi.org/10.1016/S0377-2217(98)90214-4

Belton, V.; Stewart, T. 2002. Multiple criteria decision analysis: an integrated approach. Kluwer: Academic Publishers. http://dx.doi.org/10.1007/978-1-46151495-4

Bender, A.; Din, A.; Hoesli, M.; Brocher, S. 2000. Environmental preferences of homeowners: further evidence using the AHP method, Journal of Property Investment and Finance 18(4): 445-455. http://dx.doi. org/10.1108/14635780010345391

Bin, O. 2004. A prediction comparison of housing sales prices by parametric versus semi-parametric regressions, Journal of Housing Economics 13(1): 68-84. http://dx.doi.org/10.1016/j.jhe.2004.01.001

Bourassa, S.; Cantoni, E.; Hoesli, M. 2010. Predicting house prices with spatial dependence: a comparison of alternative methods, Journal of Real Estate Research 32(2): 139-160.

Bourassa, S.; Hoesli, M.; Peng, V. 2003. Do housing submarkets really matter?, Journal of Housing Economics 12(1): 12-28. http://dx.doi.org/10.1016/S10511377(03)00003-2

Bryant, J. 1997. Requirements capture using SODA, European Journal of Information Systems 6(3): 155163. http://dx.doi.org/10.1057/palgrave.ejis.3000269

Carrillo, P.; Pope, J. 2012. Are homes hot or cold potatoes? The distribution of marketing time in the housing market, Regional Science and Urban Economics 42(1): 189-197. http://dx.doi.org/10.1016/j.regsciurbeco.2011.08.010

Catalão, A. 2010. Estudo do mercado imobiliário de Aveiro [online]. Available at http://hdl.handle. net/10773/3465 [accessed 12 September 2013].

CGD - Caixa Geral de Depósitos. 2011. Nota temática CGD: a actualidade do sector imobiliário residencial: ajustamentos e desafios [online]. Available at https:// www.cgd.pt/Research/Notas-Tematicas/Pages/SectorImobiliario-Residencial-NTNov2011.aspx [accessed 12 September 2013].

Chauhan, K.; Shah, N.; Rao, V. 2008. The analytic hierarchy process as a decision-support system in the housing sector: a case study, World Applied Sciences Journal 3(4): 609-613.

Chen, J.; Rutherford, R. 2012. Quality \& time-on-themarket in residential markets, Journal of Real Estate Finance and Economics 44(3): 414-428. http:// dx.doi.org/10.1007/s11146-010-9237-4

Cheng, P.; Lin, Z.; Liu, Y. 2008. A model of time-onmarket and real estate price under sequential search with recall, Real Estate Economics 36(4): 813-843. http://dx.doi.org/10.1111/j.1540-6229.2008.00231.x

Cheng, P.; Lin, Z.; Liu, Y. 2010. Illiquidity, transaction cost, and optimal holding period for real estate: theory and application, Journal of Housing Eco- 
nomics 19(2): 109-118. http://dx.doi.org/10.1016/j. jhe.2010.03.002

Davies, M. 1994. Using the AHP in marketing decisionmaking, Journal of Marketing Management 10(1/3): 57-63.

Dyer, R.; Forman, E. 1992. Group decision support with the analytic hierarchy process, Decision Support Systems 8(2): 99-124. http://dx.doi.org/10.1016/01679236(92)90003-8

Ebru, C.; Eban, A. 2009. Determinants of house prices in Istanbul: a quantile regression approach, Quality \& Quantity 45(2): 305-317. http://dx.doi.org/10.1007/ s11135-009-9296-x

Eden, C.; Ackermann, F. 2001. SODA - the principles, in Rosenhead, J.; Mingers, J. (Eds.). Rational analysis for a problematic world revisited: problem structuring methods for complexity, uncertainty and conflict (second edition). Chichester: John Wiley \& Sons, 21-41.

Eden, C.; Ackermann, F. 2004. Cognitive mapping expert views for policy analysis in the public sector, European Journal of Operational Research 152(3): 615-630. http://dx.doi.org/10.1016/S0377-2217(03)00061-4

Ferreira, F. 2013. Measuring trade-offs among criteria in a balanced scorecard framework: possible contributions from the multiple criteria decision analysis research field, Journal of Business Economics and Management 14(3): 433-447. http://dx.doi.org/10.384 6/16111699.2011.631744

Ferreira, F.; Santos, S.; Dias, V. 2014a. An AHP-based approach to credit risk evaluation of mortgage loans, International Journal of Strategic Property Management 18(1): 38-55. http://dx.doi.org/10.3846/164871 5X.2013.863812

Ferreira, F.; Santos, S.; Rodrigues, P. 2011. Adding value to bank branch performance evaluation using cognitive maps and MCDA: a case study, Journal of the Operational Research Society 62(7): 1320-1333. http://dx.doi.org/10.1057/jors.2010.111

Ferreira, F.; Santos, S.; Rodrigues, P.; Spahr, R. 2014b. Evaluating retail banking service quality and convenience with MCDA techniques: a case study at the bank branch level, Journal of Business Economics and Management 15(1): 1-21. http://dx.doi.org/10.38 46/16111699.2012.673504

Ferreira, F.; Spahr, R.; Santos, S.; Rodrigues, P. 2012. A multiple criteria framework to evaluate bank branch potential attractiveness, International Journal of Strategic Property Management 16(3): 254-276. http://dx.doi.org/10.3846/1648715X.2012.707629

Fiedler, F. 1965. Engineer the job to fit the manager, Harvard Business Review 43(5): 115-122.

Fiedler, F. 1967. A theory of leadership effectiveness. New York: McGraw-Hill.

Forgey, F.; Rutherford, R.; Springer, T. 1996. Search and liquidity in single-family housing, Real Estate Economics 24(3): 273-292. http://dx.doi. org/10.1111/1540-6229.00691

Forman, E.; Gass, S. 2001. The analytic hierarchy process: an exposition, Operations Research 49(4): 469486. http://dx.doi.org/10.1287/opre.49.4.469.11231
Haurin, D. 1988. The duration of marketing time of residential housing, Journal of the American Real Estate \& Urban Economics Association 16(4): 396-410. http://dx.doi.org/10.1111/1540-6229.00463

Hill, R. 2011. Hedonic prices indexes for housing, OECD Statistics Working Papers [online]. Available at http://www.oecd-ilibrary.org/economics/hedonicprice-indexes-for-housing_5kghzxpt6g6f-en [accessed 12 September 2013].

Hui, E.; Yu, K. 2012. The impact of pricing strategies on time-on-market under various economic conditions, International Journal of Strategic Property Management 16(1): 56-70. http://dx.doi.org/10.3846/164871 5X.2011.585185

Kardaras, D.; Mentzas, G. 1997. Using fuzzy cognitive maps to model and analyse business performance assessment, in Proceedings of the 2nd annual international conference on industrial engineering applications and practice II, San Diego, California, USA, 12-15 November 1997, 63-68.

Keeney, R. 1996. Value-focused thinking: Identifying decision opportunities and creating alternatives, $E$ ropean Journal of Operational Research 92(3): 537549. http://dx.doi.org/10.1016/0377-2217(96)00004-5

Leung, C.; Leong, Y.; Chan, I. 2002. TOM: Why isn't price enough?, International Real Estate Review 5(1): 91-115.

Mateu, A. 2002. ClusDM: a multiple criteria decision making method for heterogeneous data set: Ph.D. thesis. Catalunya: Polytechnic University of Catalunya.

Nandi, S.; Paul, S.; Phadtare, M. 2011. An AHP-based construction project selection method, Decision 38(1): 102-118.

Ong, S.; Chew, T. 1996. Singapore residential market: an expert judgemental forecast incorporating the analytical hierarchy process, Journal of Property Valuation and Investment 14(1): 50-66. http://dx.doi. org/10.1108/14635789610107499

Pastor-Ferrando, J.; Aragonés-Beltrán, P.; HospitalerPérez, A.; García-Melón, M. 2010. An ANP- and AHP-based approach for weighting criteria in public works bidding, Journal of the Operational Research Society 61(6): 905-916. http://dx.doi.org/10.1057/ jors. 2010.13

PEH - Plano Estratégico de Habitação 2008/2013. Sumário executivo [online]. Available at: http://habitacao.cm-lisboa.pt/index.htm?no=4005001 [accessed 12 September 2013].

Perez-Gladish. B.; M'Zali, B. 2010. An AHP-based approach to mutual funds' social performance measurement, International Journal of Multicriteria Decision Making 1(1): 103-127. http://dx.doi.org/10.1504/IJMCDM.2010.033689

Peterson, S.; Flanagan, A. 2009. Neural network hedonic pricing models in mass real estate appraisal, Journal of Real Estate Research 31(2): 148-164.

Rybak, J.; Shapoval, V. 2011. Industries and sectors: issues and policies, tendencies of real estate market development in the current context (in terms of Poland and Ukraine), Perspectives of Innovations, Economics \& Business 8(2): 17-22. 
Saaty, T. 1980. The analytic hierarchy process: planning, priority setting, resource allocation. New York: McGraw-Hill.

Saaty, T. 1994. How to make a decision: the analytic hierarchy process, Interfaces 24(6): 19-43. http://dx.doi. org/10.1287/inte.24.6.19

Saaty, T. 2008. Relative measurement and its generalization in decision making: why pairwise comparisons are central in mathematics for the measurement of intangible factors - the analytic hierarchy/network process, Real Academia de Ciencias 102(2): 251-318. http://dx.doi.org/10.1007/bf03191825

Saaty, T.; Shang J. 2011. An innovative orders-ofmagnitude approach to AHP-based mutli-criteria decision making: prioritizing divergent intangible humane acts, European Journal of Operational Research 214(3): 703-715. http://dx.doi.org/10.1016/j. ejor.2011.05.019

Schniederjans, M.; Hoffman, J.; Sirmans, G. 1995. Using goal programming and the analytical hierarchy process in house selection, Journal of Real Estate Finance and Economics 11(2): 167-176. http://dx.doi. org/10.1007/BF01098660

Shaw, D. 2004. Creativity and learning through electronic group causal mapping, International Journal of Innovation and Learning 1(4): 364-377. http:// dx.doi.org/10.1504/IJIL.2004.005497

Shiau, Y.; Tsai, T.; Wang, W.; Huang, M. 2002. Use questionnaire and AHP techniques to develop subcontractor selection system [online]. Available at http://www. iaarc.org/publications/fulltext/ISARC-2002-006.pdf [accessed 12 May 2013].

Springer, T.; Worzala, E. 2012. Measuring the elasticity of residential real estate markets under changing macro-market conditions using a varying parameter model [online]. Available at https://www.clemson. edu/centers-institutes/pennell/PDFs-2012/SpingerWorzala-ARES-2012-paper.pdf [accessed 12 September 2013].

Steuer, R.; Na, P. 2003. Multiple criteria decision making combined with finance: a categorized bibliographic study, European Journal of Operational Research 150(3): 496-515. http://dx.doi.org/10.1016/S03772217(02)00774-9

Taylor, R. 1999. Time on the market as a sign of quality, Review of Economic Studies 66(3): 555-578. http:// dx.doi.org/10.1111/1467-937X.00098

Tegarden, D.; Sheetz, S. 2003. Group cognitive mapping: a methodology and system for capturing and evaluating managerial and organizational cognition, Omega: The International Journal of Management Sciences 31(2): 113-125. http://dx.doi.org/10.1016/ s0305-0483(03)00018-5

Wang, G.; Hao, J.; Ma, J.; Jiang, H. 2011. A comparative assessment of ensemble learning for credit scoring, Expert Systems with Applications 8(1): 223-230. http://dx.doi.org/10.1016/j.eswa.2010.06.048

Warren, A. 2011. Global real estate trends: Canada's real estate market slows while most international markets stumble, Global Economic Research.

Weber, M.; Borcherding, K. 1993. Behavioral influences on weight judgments in multiattribute decision making, European Journal of Operational Research 67(1): 1-12. http://dx.doi.org/10.1016/03772217(93)90318-H

Xu, Y.; Zhang, Y. 2009. An online credit evaluation method based on AHP and SPA, Communications in Nonlinear Science and Numerical Simulation 14(7): 3031-3036. http://dx.doi.org/10.1016/j.cnsns.2008.10.018 